\title{
Enhanced advisory role urged for former EU nuclear labs
}

\section{Quirin Schiermeier}

Identifying an appropriate role for the European Commission's Joint Research Centre (JRC) has long been one of the thorniest science-related issues facing the European Union (EU).

Created in 1957 to support the development of nuclear power, the JRC now consists of eight institutes in five countries. But with nuclear power falling from political favour, the centre has increasingly lacked a clear sense of purpose. Today, only 30\% of the JRC's Euro1.02 billion ( $\$ 950$ million) budget is used for nuclear research.

The latest proposal, from an independent panel set up by EU research commissioner Philippe Busquin, is to turn the JRC into a single scientific advice and service institution directly serving the EU's three separate pillars: the European Commission in Brussels, the European Parliament and the Council of Ministers (representing member states).

"The primary function of the JRC should be to facilitate the gathering and fair assessment of information on science and technology matters to inform the EU institutions on a given scientific subject," says the panel, chaired by former industry commissioner Etienne Davignon.

Set up in January, the panel says the JRC should focus on developing monitoring systems or measurement tools in areas relevant to the security of European citizens, including health, food, environment and privacy issues.

Knowledge gathered at the JRC should be the main source of scientific information for all EU institutions, says the report. But activities should be demand-led: "The JRC should be given a remit that is related to delivering what the $[\mathrm{EU}]$ institutions say they need, not what the JRC thinks they need, as has been the case in the past."

It proposes that the JRC's non-nuclear activities should no longer be funded within the EU's Framework programmes. After 2002, it adds, the JRC's budget should reflect the needs of the three pillars of the EU.

The panel suggests that the Institute for Prospective Technological Studies in Seville, the smallest and youngest JRC institute, be responsible for providing "support and guidance" to the EU's Framework programmes for research, including the development of the sixth Framework programme for 2002-2006.

The report is being seen as a bid to start reform before the arrival of the successor to the JRC's current director Herbert Allgeier, who retires in October.

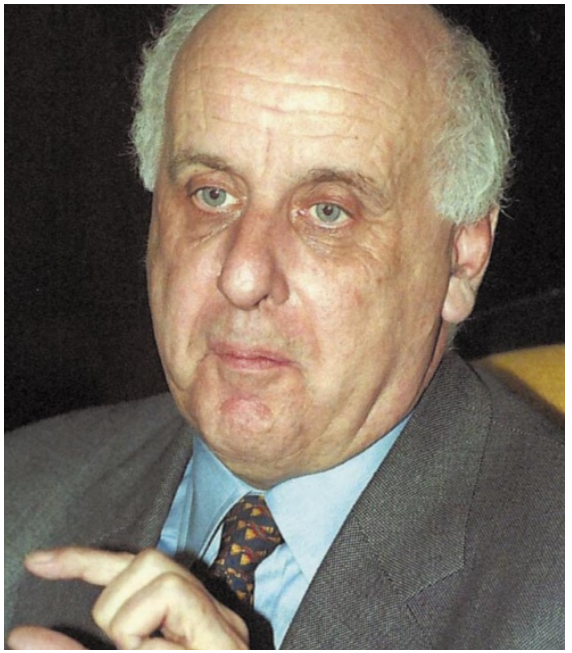

Davignon: wants unified advice for Europe.

\section{Brown boosts British science base}

\section{Natasha Loder, London}

British science figures high among the beneficiaries of a spending spree announced this week by Gordon Brown, the Chancellor of the Exchequer. Over the next three years, spending on science will average $7 \%$ more than this year in real terms, say Whitehall sources.

The figures include a $\mathfrak{E} 1$ billion ( $\$ 1.5$ billion) investment in buildings, laboratories and equipment announced last week (Nature 406, 113; 2000). But even without this money, $£ 230$ million of which comes from the Wellcome Trust, overall spending on research councils and the rest of Britain's 'science base' will be over $4 \%$ more than the previous year in each of the next three years.

Although the precise allocation of the

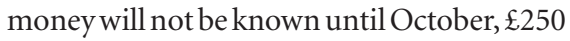
million of the increase has been earmarked for research into the advanced computing applications, known as 'the grid', and medicines based on data from the human genome.

The extra money "is clearly very encouraging", says Richard Joyner, dean of research at Nottingham Trent University and chairman of the pressure group Save British Science. But he warns that if university funding continues to decline, there is a danger of an imbalance between the money for new infrastructure and that available to run it.

In his speech, Brown said that in addition to a real increase of $5.4 \%$ in the science budget ext 200 r maxtra res Murces will be allocated to university-based innovation schemes.
Recriminations and confusion over 'fake' coelacanth photo

Heather McCabe, Paris

The hunt is on for the explanation of an apparently faked photograph of a coelacanth. The picture is alleged to be of the fish that French researchers say was discovered in Southwest Java in 1995 — three years before the first official recording of such a 'living fossil' in Indonesia by US researchers (see Nature 406, 114; 2000).

Two authors of a recent submission to Nature describing the French discovery are claiming innocence and pointing the finger at the third, while admitting that even he may have been duped. But he is also denying any wrong-doing. And the French Institut de Recherche pour le Développement (IRD), for whom all three have worked, has launched an investigation.

The submitted photograph appears to show a coelacanth lying next to three other fish typical of the region. But the image of the coelacanth is identical to a photograph taken by Mark Erdmann of the University of California at Berkeley (see Nature 395, 335; 1998).

One of the three authors of the French paper, Georges Serre, a former consultant for IRD's predecessor, ORSTROM, claims to have found the coelacanth in 1995 . He says that the specimen he caught was lost on its way to the Indonesian fishery service, and that the photos he took of the fish were stolen.

The two other authors, Bernard Séret, an ichthyologist affiliated with the IRD, and Laurent Pouyaud, an IRD geneticist who works in Jakarta, both claim that Serre either doctored the photo or knew that it was a fake, although Pouyaud also accepts that Serre may have been "manipulated".

Séret sent the photo to an independent expert affiliated with the Tribunal de Paris who asserted that it was a forgery. But Serre - who has told Séret that the photo submitted to Nature was taken by a friend who has since died - said last week that he is not yet convinced that the photo is a fake and wants a separate investigation.

Pouyaud also says that he has come across a preserved coelacanth in a private collection near Jakarta, whose owner claims that the fish originated in Java. As it was roughly the same size as the coelacanth that Serre reportedly found, he concluded that it was the same fish. 